\title{
Milk antigen absorption in the preterm and term neonate
}

\author{
D M ROBERTON, R PAGANELLI, R DINWIDDIE, AND R J LEVINSKY \\ Queen Charlotte's Hospital for Women, and Institute of Child Health, London
}

SUMMARY The concentration of $\beta$-lactoglobulin was measured in the sera of 47 preterm and term neonates during the first few days of life under standardised conditions after feeding with a cows' milk-based formula. Preterm neonates, particularly those of less than 33 weeks' gestation, had higher serum concentrations of $\beta$-lactoglobulin than term neonates given an equivalent milk feed. Prior feeding with breast milk did not diminish the amount of $\beta$-lactoglobulin absorbed. Our results suggest that the ability of the gastrointestinal tract to exclude antigenically intact food proteins increases with gestational age and that gut closure occurs normally before birth in man.

Gastrointestinal absorption of antigenically intact proteins has been shown to be increased in the neonatal period of several mammalian species. The calf and piglet, which acquire passive immunity almost exclusively from maternal milk, have a gut which is freely permeable to macromolecular proteins for the first few days post-partum. ${ }^{1}$ Feeding induces a rapid maturation of gut morphology and this results in functional gut closure to these proteins. Other species - such as the rat and mouse-have an extended period of selective absorption of immunoglobulin from maternal milk, ${ }^{2}$ which stops just before weaning. It is thought that certain factors in maternal milk enhance gut closure and indeed a species-specific effect of maternal milk on the maturation and antigen excluding function of the gut has been demonstrated in the piglet, ${ }^{3}$ beagle puppy, ${ }^{4}$ and neonatal rabbit. ${ }^{5}$

The human fetus acquires maternal immunoglobulin via the placenta during the last trimester of pregnancy. Consequently it was thought that the neonatal human gut had little need for absorption of antigenically intact food proteins. However, the potential for increased absorption in early life exists, ${ }^{6-9}$ but the evidence for it occurring is circumstantial and is based on high levels of antibodies to food proteins in preterm infants at 3-6 months after birth and the fact that these levels decline with maturity.

This study was performed to determine whether absorption of the cows' milk protein, $\beta$-lactoglobulin, from the gastrointestinal tract of human neonates under standardised conditions differed according to gestational age, birth age, or prior feeding with breast milk.

\section{Patients}

Forty-seven neonates born in three maternity hospitals were studied. Ethical committee approval was obtained from each hospital. The neonates were divided into groups according to different feeding regimens.

Group 1. Twenty-six neonates of gestational ages 30 to 39 weeks were fed by nasogastric tube, blood samples being taken after at least 4 hours of hourly feeding in an attempt to achieve an equilibrium state. The median age since first feed at the time of sampling was 26 (range 21-52) hours and the median birth age was between 31 and 32 (range 23-168) hours.

Group 2. Twelve term neonates of gestational ages 37 to 41 weeks were receiving 3-hourly or 4-hourly bottle feeds. The median age since first feed at the time of sampling was 138 (range 109-161) hours and the median birth age was 142 (range 114-164) hours.

Group 3. Nine neonates had received some breast milk during their initial feeding regimen but had not received any breast milk for at least 9 hours before sampling. Five were fed hourly by nasogastric tube (gestational age between 32 and 37 weeks) and were sampled at feeding ages between 22 and 52 hours (birth ages 29 to 172 hours). Two of these neonates had received pooled heated expressed breast milk and 3 had received fresh expressed maternal milk before artificial feeding. Four babies were bottle fed after initially suckling at the breast (gestational ages between 37 and 41 weeks) and samples were obtained 
at feeding ages of 117 to 141 hours (birth ages 119 to 146 hours).

In all babies the blood sample was taken between 25 and 35 minutes after the completion of feeding in conjunction with routine assays. All were well apart from one receiving $30 \%$ oxygen for mild hyaline membrane disease. No neonate had received any blood products. None had suffered from significant birth asphyxia and no baby had any gastrointestinal illness or known gastrointestinal abnormality. Five of the 47 neonates had birthweights below the 10th centile for gestational age. All 5 were of more than 36 weeks' gestation.

Gestational age was assessed from ultrasound measurements of biparietal diameter recorded during the pregnancy which were compared with the date of the last menstrual period. If there was a discrepancy between these estimates, a clinical scoring system was used to assess gestation. ${ }^{10}$

All babies received the same pre-packed, ready to feed, cows' milk based formula (SMA Gold Cap) as the only form of milk feeding received between birth and the time of sampling, apart from group 3 who received additional breast milk as described. The volume of feed received by each baby during the 4 hours before sampling was recorded.

All samples were capillary blood samples and serum was separated and stored at $-20^{\circ} \mathrm{C}$ until assayed.

\section{Methods}

A two-site solid phase radioimmunoassay was used to quantitate serum $\beta$-lactoglobulin concentrations. ${ }^{11}$ This assay has the advantage of being able to detect antigen when in free or in complex form especially if in antigen excess. Highly purified $\beta$-lactoglobulin (kindly supplied by the National Dairy Research Institute) was used to raise antiserum in rabbits. Specific antibody was obtained by ion-exchange chromotography followed by immunoabsorbent purification using $\beta$-lactoglobulin covalently linked to microcrystalline cellulose.

The IgG fraction of the rabbit antiserum was used to coat polyethylene microfuge tubes (Sarstedt). After overnight incubation of the test serum in the coated tubes, ${ }^{125}$ I-labelled affinity purified rabbit anti- $\beta$ lactoglobulin was added to the washed tubes and was incubated for 18 hours. The tubes were then washed and counted in an LKB gamma counter. Standard solutions of $\beta$-lactoglobulin made up in known negative sera to allow quantitation of unknown samples were included in each assay. Serum samples were coded and assayed in triplicate. The sensitivity of the assay ranged from 0.1 to $100 \mathrm{ng} / \mathrm{ml}$.

Results were expressed as nanograms of $\beta$ - lactoglobulin present per $100 \mathrm{ml}$ of serum for each one $\mathrm{ml}$ of milk given per $\mathrm{kg}$ birthweight. The Mann-Whitney U test, with correction for ties where appropriate, was used for statistical analysis. Probability values are one-tailed.

\section{Results}

Neonates in group 1 of 33 weeks' gestation or less had significantly higher serum $\beta$-lactoglobulin concentrations than the term neonates of group $1(\mathrm{P}<0.05)$ and group $2(P<0.001)$ (Fig. 1). Group 1 neonates between 33 and 37 weeks' gestation also had higher values than the group 2 neonates $(P<0.05)$.

The 12 bottle-fed term neonates of group 2 did not differ significantly from the 5 group 1 neonates of similar gestational age who had been fed by nasogastric tube.

When groups 1 and 2 were considered together, preterm neonates had significantly higher serum concentrations than did term neonates $(P<0 \cdot 002)$.

There was no correlation between serum $\beta$ lactoglobulin concentrations and birth age or feeding age within groups 1 and 2 or within the combined groups.

Earlier exposure to breast milk in the few studied

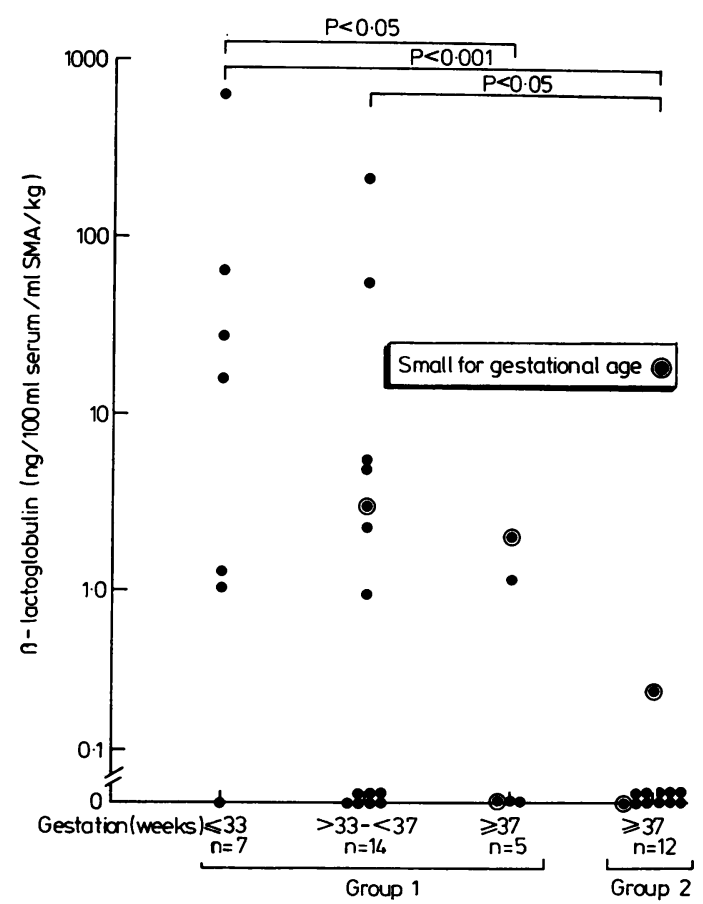

Fig. 1 Serum $\beta$-lactoglobulin concentrations per $\mathrm{ml}$ of milk given per $\mathrm{kg}$ during the preceding 4 hours (groups 1 and 2). 


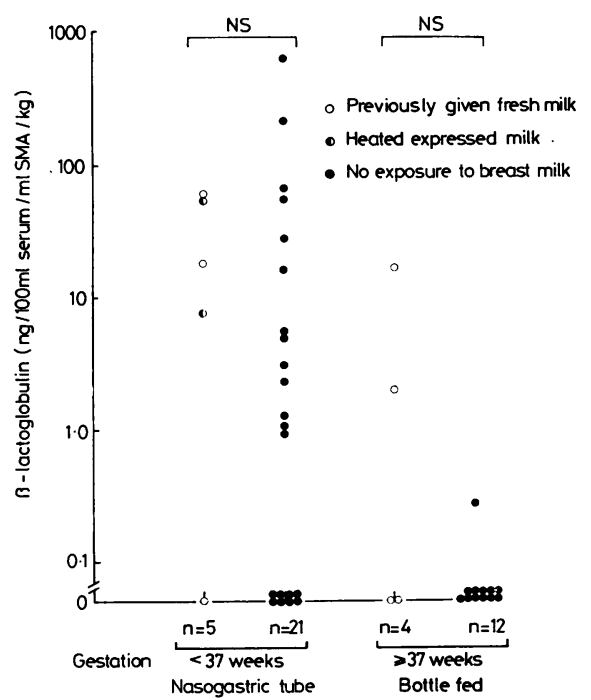

Fig. 2 Effect of prior exposure to breast milk on serum $\beta$-lactoglobulin concentrations per $\mathrm{ml}$ of milk given per $\mathrm{kg}$ in the preceding 4 hours (group 3).

in group 3 did not significantly alter the $\beta$-lactoglobulin values compared with neonates of similar gestational ages from groups 1 and 2 who had been fed by the same route at similar birth ages and had not received breast milk (Fig. 2).

Eleven of the study infants had pre-feeding samples or cord blood assayed for $\beta$-lactoglobulin and in none of these could any be detected.

\section{Discussion}

Beta-lactoglobulin (MW 36000 ) is the major whey protein of cows' milk, ${ }^{12}$ but is not found in human breast milk. This study shows that preterm neonates given an equivalent load of a cows' milk-based formula have significantly higher serum $\beta$ lactoglobulin concentrations than term neonates. In fact, the total amount of $\beta$-lactoglobulin present in the circulation of the preterm infants may be grossly underestimated since there is evidence that plasma volume with respect to weight is greater in the preterm than the term infant. ${ }^{13-15}$ The amount of antigenically intact protein absorbed by the term neonate is of the order of $10^{-5}$ of that ingested. The term neonate absorbs similar amounts to non-atopic adults given equivalent antigen loads according to body weight ${ }^{11}$ and our results indicate that absorption in the very preterm infant may be up to 100 -fold greater.

The results are therefore compatible with either increased absorption of antigenically intact proteins by the preterm infant's gut, or less efficient clearance from the circulation. Several factors may contribute to increased absorption and higher serum concentrations of $\beta$-lactoglobulin in preterm infants. Gastrointestinal motility increases and transit times decrease with advancing fetal age. ${ }^{16}$ Protein digestion in the gut lumen and at the epithelial brush border may be less efficient since stomach peptic and duodenal enteropeptidase activities are known to increase with gestation during the last trimester of pregnancy. ${ }^{17}{ }^{18}$ Epithelial cell morphology, endocytoplasmic transport, and proteolytic mechanisms may also differ at different gestational ages.

It is possible that some of the diminution in $\beta$-lactoglobulin levels with increasing gestational age is due to more effective clearance mechanisms in the more mature neonate. The antigen may be cleared by complexing with maternally derived immunoglobulin and in this respect the relationship of the lower serum $\beta$-lactoglobulin concentrations after 33 weeks' gestation found in the study and the accelerated rate of increase of total and subclass IgG concentrations known to occur at 32-33 weeks' gestation is noteworthy. ${ }^{19}$ Liver filtration may be important in the clearance of ingested antigens or antigenic fragments in the newborn ${ }^{20}$ and also may be less efficient in maturity.

Although feeding breast milk in other species has been shown to enhance gut closure in terms of morphology and function, ${ }^{3-5}$ no alteration in $\beta$-lactoglobulin levels was seen in those neonates who initially received breast milk. In the human neonate there may not be any functional enhancement of antigen exclusion attributable to breast milk factors, but the numbers studied were small and this needs confirmation. Similarly, although birth age and feeding age had no apparent effect over the narrow ranges studied in this investigation, sequential studies during longer periods of time may demonstrate lower serum values with increasing time. Xylose absorption, which is lower in preterm neonates suggesting immature absorptive cell function, has been shown recently in serial studies to rise with birth age, supporting the concept of major changes in gastrointestinal function at a cellular level in the perinatal period. ${ }^{21}$

It appears therefore, that gut closure in man is not an abrupt event but occurs gradually with fetal maturation and is normally complete by birth in the term neonate. The amounts of antigenically intact protein absorbed are insignificant nutritionally even in the preterm infant. They are however sufficient to immunise, as antibodies to food proteins may be demonstrated in most healthy individuals. ${ }^{22}$ Despite this, most people do not develop hypersensitivity responses to food proteins and a state of partial 
tolerance to oral food antigens prevails. The increased proportion of suppressor cells in the neonatal circulation may be important in this regard $^{23}$ and also as the IgA system develops so secretory IgA acts to exclude antigens within the gut lumen and that which enters is cleared without damage by forming IgA immune complexes (R Paganelli, D Atherton, R J Levinsky, 1981, unpublished data).

It is clear that the amount of intact food proteins absorbed is not related to the development of hypersensitivity reactions, since in animals sensitisation via the oral route is achieved only by low antigen doses when administered with a powerful adjuvant. ${ }^{24}$ A further factor which may determine sensitisation to milk proteins is the type of milk given since different preparations have different sensitising capabilities dependent on the method of heat treatment for sterilisation by the manufacturer. ${ }^{25}$ We do not know of any study comparing the incidence of allergy to milk proteins between preterm and term neonates, but, if this question is to be answered, the type of milk feed given to the infants must be considered. Certainly the results reported here demonstrate that $\beta$-lactoglobulin is detectable in antigenically intact form in the circulation of the human neonate despite heat treatment of the milk during whey concentration and sterilisation.

We thank the consultant paediatricians of Queen Charlotte's Hospital for Women, the City Hospital, Nottingham, and the Women's Hospital, Nottingham, for allowing neonates in their care to be enrolled in the study, and Dr M Hall, Dr C Damen-Williams, Dr V Harpin, Sister I Hopkin, and Sister M Smith for their help.

\section{References}

1 Lecce J G. Absorption of macromolecules by neonatal intestine. Biol Neonate 1966; 9: 50-61.

2 Brambell F W R. The transmission of immunity from mother to young and the catabolism of immunoglobulins. Lancet 1966; ii: 1087-93.

8 Widdowson E M, Colombo V E, Artavanis C A. Changes in the organs of pigs in response to feeding for the first 24h after birth. Biol Neonate 1976; 28 : 272-81.

4 Heird W C, Hansen I H. Effect of colostrum on growth of intestinal mucosa (abstract). Pediatr Res 1977; 11 : 406.

5 Udall J N, Pang K, Scrimshaw N S, Walker W A. The effect of early nutrition on intestinal maturation (abstract). Pediatr Res 1979; 13: 409.

- Moxey P C, Trier J S. Development of villus absorptive cells in the human fetal small intestine: a morphological and morphometric study. Anat Rec 1979; 195: 463-82.

7 Walker W A. Gastrointestinal host defence: importance of gut closure in control of macromolecular transport. In: Elliott R M, Whelan J, eds. Development of mammalian absorptive processes. Ciba Foundation Symposium 70. Amsterdam: Excerpta Medica, 1979: 201-19.
8 Rothberg R M. Immunoglobulin and specific antibody synthesis during the first weeks of life of premature infants. J Pediatr 1969; 75: 391-9.

9 Eastham E J, Lichauco T, Grady M I, Walker W A. Antigenicity of infant formulas: role of immature intestine on protein permeability. $J$ Pediatr 1978; 93: $561-4$.

10 Dubowitz L M, Dubowitz V, Goldberg C. Clinical assessment of gestational age in the newborn infant. J Pediatr 1970; 77: 1-10.

11 Paganelli R, Levinsky R J. Solid phase radioimmunoassay for detection of circulating food protein antigens in $\vec{\circ}$ human serum. J Immunol Methods 1980; 37: 333-41.

12 Lyster R L J. Reviews of the progress of dairy science. $\vec{\omega}$ Section C. Chemistry of milk proteins. J Dairy Res 1972; 39: 279-318.

13 Mollison P L, Veall N, Cutbush M. Red cell and plasma volume in newborn infants. Arch Dis Child 1950; 25: G $242-53$.

14 Sisson T R C, Whalen L E, Telek A. The blood volume of ir infants. II. The premature infant during the first year of life. J Pediatr 1959; 55: 430-46.

15 Sisson T R C, Lund C J, Whalen L E, Telek A. The blood 을 volume of infants. I. The full-term infant in the first year of life. J Pediatr 1959; 55: 163-79.

16 McClain C R, Jr. Amniography studies of the gastrointestinal motility of the human fetus. Am $J$ Obstet Gynecol 1963; 86: 1079-87.

17 Werner B. Peptic and tryptic capacity of the digestive glands in newborns. Acta Paediatr Scand 1948; 35: Supplement 6, 1-80.

18 Antonowicz I, Lebenthal E. Developmental pattern of small intestinal enterokinase and disaccharidase activities in the human fetus. Gastroenterology 1977; 72: 1299-303.

19 Chandra R K. Levels of IgG subclasses, IgA, IgM, and tetanus antitoxin in paired maternal and foetal sera: findings in healthy pregnancy and placental insufficiency. In: Hemmings W A, ed. Materno-foetal transmission of immunoglobulins. London: Cambridge University Press, 1976: 77-90.

20 Udall J N, Fritze L, Pang K, Walker W A. Neonatal host defense: the role of the liver (L) as a molecular sieve for the removal of antigens (A) and antigenically-active fragments (AF) (abstract). Pediatr Res 1980; 14 : 512.

21 Ducker D A, Hughes C A, Warren I, McNeish A S. O Neonatal gut function measured by the one hour blood 3 D ( + ) xylose test: influence of gestational age and size. Gut 1980; 21 : 133-6.

22 Peterson R D A, Good R A. Antibodies to cows' milk proteins - their presence and significance. Pediatrics 1963; $ᄋ$ 31: 209-21.

23 Hayward A R, Lawton A R. Induction of plasma cell $\frac{D}{O}$ differentiation of human fetal lymphocytes. Evidence for functional immaturity of T and B cells. J Immunol 1977; N 119: 1213-7.

24 Jarrett E E E. Activation of IgE regulatory mechanisms N by transmucosal absorption of antigen. Lancet 1977; ii: N 223-5.

25 McLaughlan $P$, Anderson $K \mathbf{J}$, Widdowson $\mathbf{E} \mathbf{M}$, Coombs R R A. Effect of heat on the anaphylactic- 0 sensitising capacity of cows' milk, goats' milk, and various infant formulae fed to guinea pigs. Arch Dis Child o 1981 ; 56: 165-71.

Correspondence to Dr R J Levinsky, Department of Immunology, Institute of Child Health, 30 Guilford Street, London WC1N 1EH.

Received 24 August 1981 